\title{
Evaluation of Tourism Eco-efficiency in Yangshuo County from the Perspective of Carbon Footprint
}

\author{
Xiaoying Han ${ }^{1}$, Jinye Wang1, and Ning $\mathrm{Li}^{2,3,{ }^{*}}$ \\ ${ }^{1}$ College of Tourism, Guilin University of Technology, Guilin 541006, China \\ ${ }^{2}$ Bowen College of Management Guilin University of Technology, Guilin 541006, China \\ ${ }^{3}$ Key Laboratory of spatial information and mapping of Guangxi, Guilin 541006, China
}

\begin{abstract}
According to the input-output theory, the paper quantitatively analyzes the tourism ecoefficiency of Yangshuo in 2017 by building a tourism eco-efficiency model based on carbon footprint. The research shows that: Firstly , the total carbon footprint of tourism traffic in 2017 is $791.22 \times 10^{6} \mathrm{~kg}$; the total carbon footprint of tourism accommodation is $353.60 \times 10^{6} \mathrm{~kg}$; the total carbon footprint of tourism activities is $123.29 \times 10^{6} \mathrm{~kg}$.Secondly, the 2017 tourism eco-efficiency of the Yangshuo County is $8.05 \mathrm{RMB}$ per kilogram. It refers to the economic profit is $8.05 \mathrm{RMB}$ when 1 kilogram of carbon dioxide is produced, which is relatively efficient compared with other regions. Lastly, the paper makes suggestions with regarding to the optimization of the tourism eco-efficiency.
\end{abstract}

\section{Introduction}

In recent years, people are more and more concerned about the tourism environment with the rapid development of the tourism industry. As an indicator of sustainable development, tourism eco-efficiency has guiding significance for tourism sustainable development ${ }^{[1]}$. At present, scholars at home and abroad adopt various methods to study tourism eco-efficiency in different aspects. Scholars such as Gossling who built up the carbon footprint model held the view that there were many influences on the differences of the tourism ecoefficiency by quantitative calculation of France, the Rocky Mountain National Park and the Republic of Seychelles ${ }^{[2]}$. Through a research on the tourists' activities and the carbon intensity in New Zealand, Becken and Simmons found that there were a huge gap in the average consumption intensity between the $7 \mathrm{MJ}$ of the tourism hub and the $130 \mathrm{MJ}$ of the hung gliding ${ }^{[3]}$.In the case of Davos, Switzerland in the Alps region, Kytzia evaluated the strategy of the tourism ecoefficiency with the model of IOA(Input -Output Analysis $)^{[4]}$.Lipeng, Yang Guihua, Xiao Jianhong, Jiang Meisu, Zhenyu, Libin and Chen Dongjing measured the eco-efficiency with the single index method ${ }^{[5-8]}$. As China's advanced demonstration area of national ecological conservation, the Yangshuo county boasts abundant natural, cultural resources and especially numerous tourism resources. Therefore, making the assessment of the tourism eco-efficiency is beneficial to the sustainable development of regional tourism.

\section{Regional overview and method}

\subsection{Basic situation of Yangshuo}

Yangshuo County, south of Guilin City, is a county under the jurisdiction of Guilin City, in the northeast of Guangxi Zhuang Autonomous Region, China(Fig. 1). The Yangshuo County has a gifted and geographical advantage for its convenient transportation, comfortable climate and profound cultural background. Moreover, the county has enjoyed the praise of "Guilin's scenery is best among all under heaven" since ancient times, and it is also a famous scenic county in China. Because of its breathtaking sights, the Yangshuo ranks tops the 1st for the "China's most beautiful counties". In the Yangshuo County, there are 17 rivers flowing down the 20 thousand majestic high mountains. Therefore, there are over 150 beautiful scenic spots. With the Li River surrounded by karst peaks, visitors are easily accessible to enjoy the typical karst landscape. This is why the saying of "Yangshuo is famous for its thousands of hills and carves, and numerous scenic spots and lakes."lies in.

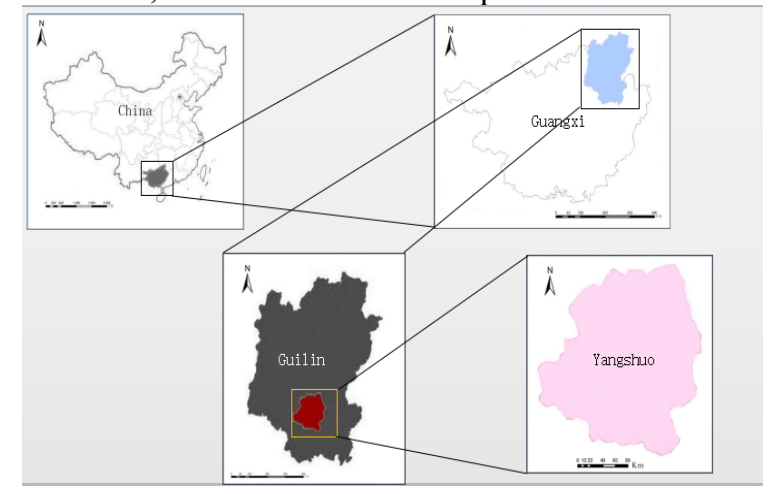

Fig. 1. The geographical location of Yangshuo.

\footnotetext{
* Corresponding author: guilinlining@163.com
} 


\subsection{Data sources}

The data comes from the 2017 Yangshuo County Tourism Bureau, the questionnaire survey of tourists, the field survey of the scenic spot, and the relevant authoritative documents. The calculation of tourism ecoefficiency requires two kinds of data, one is carbon footprint and the other is tourism income. Statistics such as methods of transportation, types of accommodation, types of tourism activities, lingering days are obtained through questionnaire surveys and scenic area surveys; the $\mathrm{CO}_{2}$ emission factors, balance factors are from previous studies, which will be used to calculate carbon emissions. The domestic tourism revenue and the total number of domestic tourists are obtained from Yangshuo Tourism Bureau. The paper mainly studies the effect of domestic tourists on the eco-efficiency of tourism in Yangshuo County. Therefore, the tourist inbound tourists and the income from entry are not within their scope of calculation.

Carbon footprint refers to the total greenhouse gas emissions including carbon dioxide caused by individuals in needs of life or work ${ }^{[10]}$. The tourism carbon footprint is defined as the total emissions of carbon dioxide caused by people's travelling directly or indirectly. In this paper, a single index method is used to establish a tourism ecological efficiency model based on carbon footprint and evaluate the tourism ecological efficiency of Yangshuo County.

\subsection{The tourism eco-efficiency and carbon footprint}

Tourism eco-efficiency is an important indicator to measure environmental and economic output, and its purpose is to make tourism use the minimum environmental impact to maximize economic value, which is a fundamental tool for assessing the sustainable development of tourism. The development of the tourism eco-efficiency comes from the eco-efficiency, both of whose definition is unclear. At present, the definition of the community basically follows the WBCSD's definition of ecological efficiency, that is, the minimum environmental impact to create the greatest value ${ }^{[9]}$.

\subsection{Tourism carbon footprint model}

\subsubsection{Traffic}

Combined with previous research results $[11,12,13]$, the carbon footprint model of tourism traffic is defined as:

$$
T_{a}=\sum_{\mathrm{k}} \varepsilon_{k} \cdot N_{k} \cdot D_{k} \cdot \alpha_{k}
$$

$\mathrm{T}_{\mathrm{a}}$ : the carbon footprint of tourism transportation. $\mathrm{N}_{\mathrm{k}}$ : the amount of the distance of the $\mathrm{k}$ band transportation. $\alpha_{k}$ : the density of carbon dioxide for the $\mathrm{k}$ band transportation. $\varepsilon_{\mathrm{k}}$ : the equivalent factor of the $\mathrm{k}$ band transportation, which plays the role of reducing the variation in calculation as is shown in table $1[11,13]$.
Table 1. Factors for different transport modes.

\begin{tabular}{|c|c|c|}
\hline $\begin{array}{c}\text { Traffic } \\
\text { type }\end{array}$ & $\begin{array}{c}\text { Emission factor } \\
\alpha_{\mathrm{k}}, \mathrm{CO}_{2}(\mathrm{~kg} / \mathrm{pkm})\end{array}$ & $\begin{array}{c}\text { Equivalence } \\
\text { factor, } \varepsilon_{\mathrm{k}}\end{array}$ \\
\hline Air & 0.150 & 2.7 \\
\hline Rail & 0.025 & 1.05 \\
\hline Car & 0.075 & 1.05 \\
\hline Coach & 0.018 & 1.05 \\
\hline
\end{tabular}

\subsubsection{Accommodation}

The carbon footprint of tourism accommodation refers to the carbon emissions of using electricity and water produced by tourists in their accommodations. Its model is:

$$
T_{b}=\sum_{\mathrm{i}} N_{i} \cdot H_{i} \cdot \beta_{i}
$$

$\mathrm{T}_{\mathrm{b}}$ : the carbon footprint of tourism accommodation. $\mathrm{N}_{\mathrm{i}}$ : the amount of visitors by the $\mathrm{i}$ band of the transportation ways. $\mathrm{H}_{\mathrm{i}}$ : the average lingering time of visitors by the $\mathrm{i}$ band of the transportation ways. $\beta_{\mathrm{i}}$ : the carbon emission amount of visitors when they linger for one night by the $i$ band of the transportation ways.

\subsubsection{Activities}

Nowadays, the carbon emissions generated by tourists participating in different types of tourism activities are different as more and more tourism activities emerge. In this paper, the carbon footprint of every tourist participating in a tourism activity is taken as the carbon footprint coefficient of the activity, using following equation:

$$
T_{c}=\sum_{\mathrm{j}} N_{j} \cdot r_{j}
$$

$\mathrm{T}_{\mathrm{c}}$ : the carbon footprint of tourism activities. $\mathrm{N}_{\mathrm{j}}$ : the amount of tourists that take part in the $\mathrm{j}$ band activity. $\Upsilon_{j}$ : the carbon emissions that every tourist participates in the $\mathrm{j}$ band tourism activity.

\subsection{Tourism eco-efficiency model}

The eco-efficiency is an index of measuring economy and ecological environmental environment. The measure method of ecological efficiency is not unified, and the model of WBCSD is generally accepted by scholars from various circles.It is[9]:

\section{Eco-efficiency=the values of products or}

service/the environmental influence.

To research the tourism eco-efficiency, we should not only substitute the influence of the environment with the carbon emissions, but also substitute the values of products or service with tourism income. Therefore, the tourism eco-efficiency model is: 


$$
T_{E e}=T_{R} / T_{E}
$$

$\mathrm{T}_{\mathrm{Ee}}$ : the tourism eco-efficiency; $\mathrm{T}_{\mathrm{R}}$ : the tourism income, $\mathrm{T}_{\mathrm{E}}$ :Tourism carbon footprint.

\section{Tourism eco-efficiency assessment}

\subsection{Traffic carbon footprint}

In this paper, the carbon footprint of tourism traffic is divided into the indoor and outdoor traffic carbon footprint. The outdoor traffic carbon footprint refers to the $\mathrm{CO}_{2}$ emissions generated by tourists who do not enter Guilin City, while indoor traffic refers to the $\mathrm{CO}_{2}$ emissions generated by tourists from Guilin City to Yangshuo County. In order to simplify the calculation, the starting point of tourists from outside the city is unified as the capital city, the indoor traffic takes the Guilin Railway Station as the starting point. Combined with questionnaire survey and previous research, it is calculated that the tourist traffic carbon footprint of Yangshuo from tourists in Guangxi, Guangdong, Hunan, Shanghai, Guizhou, and Yunnan in 2017 is $104.30 \times 10^{6} \mathrm{~kg}, \quad 52.76 \times 10^{6} \mathrm{~kg}, \quad 17.60 \times 10^{6} \mathrm{~kg}, \quad$ and $530.51 \times 10^{6} \mathrm{~kg}, 4.87 \times 10^{6} \mathrm{~kg}, 31.52 \times 10^{6} \mathrm{~kg}$; the indoor traffic carbon footprint is $47.49 \times 10^{6} \mathrm{~kg}$. The carbon footprint of different modes of transportation is shown in table 2. Finally, the paper conclude that the total carbon footprint of tourist traffic is $791.22 \times 10^{6} \mathrm{~kg}$.

Table 2. Traffic carbon footprint.

\begin{tabular}{|c|c|}
\hline Traffic type & Carbon footprint $\left(\times 10^{6} \mathrm{~kg}\right)$ \\
\hline Air & 554.02 \\
\hline Rail & 81.05 \\
\hline Car & 19.48 \\
\hline Coach & 138.67 \\
\hline
\end{tabular}

\subsection{Accommodation carbon footprint}

The resources such as hydropower resources and others, which bring economic benefits to tourism accommodation, are important sources of carbon footprint. According to the results of the investigation, the carbon footprint of different types of tourist accommodation is calculated by using the carbon footprint model of tourism accommodation (Table 3) . The total carbon footprint of tourism accommodation is $353.60 \times 10^{6} \mathrm{~kg}$.

Table 3. Accommodation carbon footprint.

\begin{tabular}{|c|c|}
\hline $\begin{array}{c}\text { Accommodation } \\
\text { type }\end{array}$ & Carbon footprint $\left(\times 10^{6} \mathrm{~kg}\right)$ \\
\hline Five-star hotel & 67.88 \\
\hline $\begin{array}{c}\text { Three or four-star } \\
\text { hotel }\end{array}$ & 53.96 \\
\hline Economical hotel & 231.76 \\
\hline
\end{tabular}

\subsection{Activity carbon footprint}

Although there is not much carbon footprint caused by tourist activities, it means a lot to tourism as a part of it. Researches show that different activities have different carbon footprint (Table 4). Besides, the amount of carbon footprint caused by tourism activities is $123.29 \times 10^{6} \mathrm{~kg}$.

Table 4. Activity carbon footprint.

\begin{tabular}{|c|c|}
\hline Activity type & Carbon footprint $\left(\times 10^{6} \mathrm{~kg}\right)$ \\
\hline Sightseeing & 8.41 \\
\hline $\begin{array}{c}\text { Watching } \\
\text { performances }\end{array}$ & 1.82 \\
\hline $\begin{array}{c}\text { Sightseeing by } \\
\text { ship }\end{array}$ & 80.73 \\
\hline River drifting & 19.48 \\
\hline Fishing & 12.85 \\
\hline
\end{tabular}

\subsection{Tourism eco-efficiency}

Tourism eco-efficiency is the result of measurement and analysis of tourism traffic, tourist accommodation, tourism activity carbon footprint and tourism income. Here the tourism income refers to domestic tourism income. As it's difficult to get the ratios of the tourism departments, people substitute the total amount of the tourism transportation, accommodations and activities with the domestic income. Maybe the data is not very accurate, but it is still representative. Results show that in 2017, the total amount carbon footprint of tourism transportation, accommodations and activities is $1268.11 \times 10^{6} \mathrm{~kg}$. Since the domestic tourism income is 10.21 billion yuan, the tourism eco-efficiency of the Yangshuo County in 2017 is 8.05 yuan per kilogram, which means that the average economic income is 8.05 yuan when 1 kilogram is produced.

\subsection{Regional difference}

Scholars at home and abroad analyzed the tourism ecoefficiency for such scenic spots as the Hainan province $^{[13]}$, Zhoushan Islands ${ }^{[5]}$, Huangshan and Jiuzhai Jiuzhaigou tourist area ${ }^{[14]}$, Seychelles ${ }^{[11]}$ and Zhangjiajie $^{[15]}$. Studies show that their eco-efficiency values are 1.787, 27.10, 4.953 and 3.269, 1.049 and 51.28 RMB per kilogram respectively. The paper shows that the tourism eco-efficiency of Yangshuo County in 2017 is 8.05 yuan $/ \mathrm{kg}$, which is higher than Huangshan and Jiuzhaigou tourist area, Seychelles and Hainan province, and lower than the Zhoushan Islands and Zhangjiajie. At the same time, compared with the average global eco-efficiency $(1.43 \$ / \mathrm{kg}, 11.44$ yuan $/ \mathrm{kg})$ and the average domestic eco-efficiency $(0.38 \$ / \mathrm{kg}, 3.04$ yuan $/ \mathrm{kg}$ ), the tourism ecological efficiency of Yangshuo County in 2017 is lower than the global eco-efficiency and higher than the domestic eco-efficiency. Therefore, the tourism eco-efficiency of Yangshuo County in 2017 
is relatively high efficient.Finally, according to the "2016-2017 China Travel Consumer Market Development Report" issued by China Tourism Research Institute, the article estimates that the total income of Yangshuo County's tourism traffic, tourism accommodation, and tourism activities accounts for 55\% of the total domestic tourism revenue of Yangshuo County, and the tourism eco-efficiency of Yangshuo county is 4.42 yuan $/ \mathrm{kg}$, so it is relatively efficient.

\section{Conclusions and discussion}

1)From the perspective of tourism department, the carbon emission of tourism transportation is greater than that of tourism accommodation and tourism activities. Therefore, when the travel distance is certain, the measures to optimize the ecological efficiency of tourism lie in improving the service quality, increasing the experience related to tourism, improving the consumption level of tourism and extending the stay time. In addition, when the price of tourism products is set, the energy needed in tourism transportation, tourist accommodation, and tourism activities should be as low as possible, which will increase the utilization ratio of facilities, enhance the utilization of wastes, and reduce the amount of carbon emitted from tourism. And then improve the tourism eco-efficiency.

2)The tourism eco-efficiency of the Yangshuo county is relatively high compared with other regions. This is mainly due to the inaccuracy of the total income of tourism transportation, tourism accommodation, and tourism activities in the measurement process; factors such as tourism, catering, entertainment, and shopping are not considered. In addition, tourism ecological efficiency is a complex system. If water resources, land resources and energy consumption are used as input indicators, tourism income, environmental improvement, creative employment opportunities and so on are taken as output indicators, it will be more accurate to calculate the tourism eco-efficiency.

3)The eco-efficiency only involves the economy and the environment, while tourism as an activity must consider the society and the ecology. Only in this way can the tourism eco-efficiency show the eco-efficiency of the sustainable development of the tourism industry more completely to provide precise data for further reference. In the meantime, by analyses of the tourism eco-efficiency based on time and space, the and problems can be showed to improve the intrinsic law sustainable development of tourism. However, the studies of the tourism eco-efficiency in a specific time frame are unable to expose its development trends in the future ${ }^{[16]}$

\section{Acknowledgment}

This work is supported by the National scientific and technological support projects (2012BAC16B04), the Guangxi education department youth teacher basic ability improvement project (2017KY1360) and GuangXi Key Laboratory of Spatial Information and
Geomatics Program (Contract No. GuiKeNeng 151400734, 163802518 and 163802531).

\section{Reference}

1. L. Zhi .Study on Sustainable Development of Tourism in Hongcun, Anhui [D]. Anhui Finance and Economics University, (2016)

2. S. Gossling Gobal Environmental Consequences of Tourism [J].GEC, 4(2002)

3. S. Becken, D.G. Simmons. Understanding Energy Consumption Patterns of Tourist Attractions and Activities in New Zea-land [J]. TM, 4(2002)

4. L. Peng, Y. Guihua, Z. Biao. GHG Emission Based Eco-efficiency Study on Tourism Itinerary Products in Shangri-La, Yunnan Province, China [J], AES, 5(2008)

5. X. Jianhong, Y. Aifen, W. Min. Carbon Footprint Evaluation in Tours: A Case Study of Zhoushan Islands [J].TS, 4(2011)

6. J. Sumei, X. Ling. Study of Eco-efficiency of Tourism Industry: Taking Kunming as An Example [J].TR, 2(2014)

7. Z. Yi. On Tourism Eco-efficiency Based on Greenhouse Gas Emission[J]. JOAAS, 8(2013)

8. L. Yongpeng, T. Jun, C. Yue, et al. Regional Sustainability Based on Comprehensive Measurement of Background Ecological Footprint and Tourism Ecological Footprint:A Case Study of Southeast Qian [J].JOMS, 6(2007)

9. WBCSD. Eco-efficiency:Creating More Value with Less Impact [R]. Geneva:WBCSD, (2000)

10. B.P. Weidema, M. Thrane, P. Christensen et al.Carbon Footprint: A Catalyst for Life Cycle Assessment?[J].JOIE, 1(2008)

11. S. Gossling, P. peeters, J.P. Ceron et al. The Ecoefficiency of Tourism[J].EE, 54(2005)

12. T.P. Lin. Carbon Dioxide Emissions from Transport in Taiwan's National Park [J]. TM, 31(2010)

13. Y. Zhiguo, C. Tian, Y. Shuobing, L. Xingang. Emprical Analysis of Regional Tourism Ecoefficiency:Taking Hainan Province as an Example, [J]. GS, 3(2016)

14. Z. Jinhe, Evaluation of Ecological Impact of Tourism Waste--Taking JiuZhaigou and Huangshan Science Spots as Examples [J].AES, 6(2008)

15. Z. Yi. Toursim Eco-effiency Assessment: A Comparative Study Based on Ecological Footprint and Carbon Footprint [J]. FEI, 5(2014)

16. Z. Jinhe, Z. Jie. Tourism Ecological Footprint Model and Empirical Analysis of Huangshan City [J]. GJ, 5(2004) 